\title{
Cuando la resiliencia se hizo postal
}

\author{
Veronica Hurtubia-Toro \\ Unidad de Investigación sobre la Resiliencia, UCSC. Italia. https://orcid.org/0000-0002-2994-1707 \\ Judit Onsès \\ Universitat de Barcelona. España. https://orcid.org/0000-0001-5681-2356 \\ Anna Forés-Miravalles \\ Universitat de Barcelona. España. https://orcid.org/0000-0001-6607-8132
}

Artículo de Investigación. Recibido: 23/10/2021. Aceptado: 12/01/2022. Publicación avanzada: 03/03/2022. Publicación: 01/07/2022.

\begin{abstract}
Resumen
INTRODUCCIÓN. La pandemia Covid-19 impactó en lo físico, emotivo y social. Las medidas de distanciamiento modificaron las formas de relacionarse, produciendo, al comienzo, estrés y temores frente a la incertidumbre que impactaron, también, en la esfera educativa. La mayoría de las investigaciones se han focalizado en las consecuencias negativas del distanciamiento en la salud mental de las personas. Por esto, el presente artículo presenta una mirada diferente que, desde la resiliencia, indaga cómo los sujetos construyen nuevas relaciones de apoyo gracias a las posibilidades que ofrece el espacio educativo. En concreto, lo hace mediante un intercambio de postales entre estudiantes de la Università Cattolica Sacro Cuore di Milano y la Universitat de Barcelona, desde marzo a mayo del 2020.
\end{abstract}

MÉTODO. Estudio de corte cualitativo, análisis textual y visual de postales, con el objetivo de explorar las potencialidades de las postales como método creativo y de fomento de la resiliencia.

RESULTADOS y DISCUSIÓN. Se arrojan indicios sobre la creación de vínculos afectivos y la activación de estrategias de empatía frente al confinamiento, posicionando las postales como un instrumento de resiliencia. Demostrando, también, cómo los métodos creativos fomentan otros modos de relación, frente a métodos más tradicionales de investigación.

\section{Palabras clave}

Resiliencia, COVID-19, Confinamiento, Vínculo, Educación.

\section{Referencia recomendada}

Hurtubia-Toro, V., Onsès, J., y Forés-Miravalles, A. (2022). Cuando la resiliencia se hizo postal. REIRE Revista d'Innovació i Recerca en Educació, 15(2), 1-18. https://doi.org/10.1344/reire.36980

(C) 2022 Las autoras. Este artículo es de acceso abierto sujeto a la licencia Reconocimiento 4.0 Internacional de Creative Commons, la cual permite utilizar, distribuir y reproducir por cualquier medio sin restricciones siempre que se cite adecuadamente la obra original. Para ver una copia de esta licencia, visite 


\section{Títol (català)}

Quan la resiliència es va fer postal

\section{Resum}

INTRODUCCIÓ. La pandèmia per la covid-19 ha impactat en l'aspecte físic, emocional i social. Les mesures de distanciament han modificat les formes de relacionar-se i van produir estrès i pors davant la incertesa que van impactar, també, en l'esfera educativa. La majoria de les investigacions s'han focalitzat en les conseqüències negatives que ha tingut el distanciament en la salut mental de les persones. Per això, aquest article presenta una mirada diferent, que, des de la resiliència, indaga com els subjectes construeixen noves relacions de suport gràcies a les possibilitats que ofereix l'espai educatiu. En concret, ho fa mitjançant l'intercanvi de postals entre estudiants de la Università Cattolica Sacro Cuore di Milano i la Universitat de Barcelona, entre març i maig del 2020.

MÈTODE. Estudi de tall qualitatiu, amb anàlisi textual i visual. L'objectiu és explorar les potencialitats de les postals com a mètode creatiu i de foment de la resiliència.

RESULTATS i DISCUSSIÓ. Es mostren les postals com un instrument de resiliència. Es donen indicis sobre la creació de vincles afectius i l'activació d'estratègies d'empatia davant del confinament. També es demostra com els mètodes creatius fomenten altres tipus de relació i comprensió, davant de mètodes més tradicionals d'investigació.

\section{Paraules clau}

Resiliència, COVID-19, Confinament, Vincle, Educació

\section{Title (English)}

Resilience in the form of a postcard

\section{Abstract}

INTRODUCTION. The Covid-19 pandemic had a profound physical, emotional and social impact. The lockdown measures modified ways of relating to others, increasing levels of stress and anxiety. The uncertainty also impacted the educational sphere. Most research has focused on the negative consequences of lockdown on individuals' mental health. The present article proposes a different view; from the perspective of resilience, it investigates how the subjects build new supportive relationships thanks to the possibilities offered by the educational space. The study is based on a postcard exchange between students of the Università Cattolica Sacro Cuore di Milano and the Universitat de Barcelona, from March to May 2020.

METHOD. The aim of this qualitative study, consisting of a textual and visual analysis of the postcards, is to explore their potential as a creative and dispositional vehicle to foster resilience.

RESULTS and DISCUSSION. The postcards emerge as instruments of resilience, providing examples of the creation of affective bonds and the activation of empathy strategies in the face of the lockdown situation. The study also shows that creative methods foster other modes of relationship and understanding versus more traditional methods of inquiry.

\section{Keywords}

Resilience, COVID-19, Lockdown, Peer relationship, Education 


\section{Introducción}

El 11 de marzo de 2020 la Organización Mundial de la Salud declaró oficialmente al COVID-19 una pandemia, modificando drásticamente los hábitos cotidianos de las personas en todo el mundo (World Health Organization [WHO], 2020). Entre los meses de marzo y mayo comienza la difusión del COVID-19 en Europa, y los primeros países más afectados fueron España con 28.700 muertes e Italia con 32.700 en ese período (European Centre for Disease Prevention and Control, 2020). Por ello, a partir de esa fecha los gobiernos comenzaron a tomar diversas medidas sanitarias y a reducir las situaciones de contacto social con el objetivo de limitar la difusión de la enfermedad. Estas medidas - voluntarias y obligatorias - significaron una reducción radical de las formas de contacto social con el cierre de bares y restaurantes, cancelación de eventos masivos como conciertos, cierre de cines y teatros, además de escuelas y universidades que pasaron de la modalidad presencial de aprendizaje a la online. Las comunidades comenzaron a buscar nuevas formas de interacción social que no significaran contacto físico.

Las medidas de distanciamiento social adoptadas por los gobiernos limitaron las formas de interacción social de todo el mundo; el cierre de los espacios de sociabilización, la imposibilidad de visitar parientes, la adopción de la modalidad de teletrabajo y el confinamiento total hizo que muchas personas o familias se sintieran aisladas, sin un apoyo social, impactando directamente en la salud mental de los sujetos (Brooks et al., 2020; Goldschmidt, 2020). Recientes estudios confirman que, en España e Italia, el 86 \% de los padres observó cambios emocionales y de conducta en sus hijos (Orgilés et al., 2020). Esta situación también afectó a los estudiantes universitarios en varias dimensiones: emocional, social y psicológicamente (Save the Children, 2020).

Ante este hecho insólito, la Organización para la Cooperación y el Desarrollo Económicos ([OCDE], 2020) señala que sólo una educación resiliente y responsiva podrá dar respuesta al actual mundo en crisis y en constante cambio al que nos enfrentamos. Por otro lado, las Naciones Unidas (2020) proponen entre otras acciones "crear sistemas resilientes de educación para lograr un desarrollo equitativo y sostenible" y "repensar la educación y acelerar el cambio en la enseñanza y el aprendizaje" (p. 4).

Frente al nuevo contexto generado por el COVID-19 y los cambios consecuentes en la forma en que se tejen y cultivan las relaciones entre sujetos, sobre todo en el ámbito social y educativo, la resiliencia aparece como un concepto fundamental para gestionar los desafíos que imponen las nuevas limitaciones sociales. Es un concepto fácil de explicar, pero más difícil de promover y más en el ámbito educativo universitario, como expresa el gran referente de resiliencia, Boris Cyrulnik (2002): "La resiliencia no es un catálogo de las cualidades que pueda poseer un individuo. Es un proceso que, desde el nacimiento hasta la muerte, nos teje sin cesar, uniéndonos a nuestro entorno" (p. 209). Para hacer ese proceso de resiliencia existen muchas estrategias y técnicas, pero lo fundamental es el lazo afectivo, el vínculo, la alteridad, el otro o los otros. En palabras del mismo autor: "El factor de resiliencia más eficaz, el que encontramos regularmente en los estudios hechos a largo plazo, es el tejido de un vínculo afectivo estable" (Cyrulnik, 2011, p. 93).

De este modo, el vínculo y la afectividad emergen como dos pilares de resiliencia básicos y fundamentales no sólo para prevenir los traumas sino para el pleno desarrollo emocional sano de las personas. Si lo pudiéramos resumir en tres parámetros serían: "el desarrollo del sujeto y su historia pretraumática, la estructura del trauma y la organización del apoyo postraumático" (Cyrulnik, 2009, p. 50). La promoción de la resiliencia y sus pilares necesita de herramientas que actúen como catalizadores del proceso comunicando lo que hay en el mundo interior de la persona a los demás. En este sentido, el arte permite una movilización interna y externa: "la que mantiene la emoción a distancia y permite que nos adueñemos de la situación. Así, realizamos un trabajo de resiliencia. Porque la emoción se transforma, se metamorfosea" (Cyrulnik, 2010, p.73). O, de acuerdo con López- 
Fernández-Cao (2015): "crear es atreverse a reiniciar sin ruptura pero señalando una nueva manera de estar, un ejercicio que puede hacer estallar las estructuras previas, por ello es elemento inseparable de la libertad humana" (p. 68).

El arte modifica esa expresión de la memoria herida, del presente cruel o sacudido por el no control. Cuando se crea una obra de arte - en este caso una postal-, el autor crea una nueva interpretación de la realidad que le ayuda a sanar la herida o el dolor: "Sanar, comprender y conocer se vuelven sus armas de libertad" (Cyrulnik, 2015 , p. 236). Ahora bien, ese acto también implica un relato común que puede favorecer la resiliencia o imposibilitarla: "Esto significa que la forma en que todo el mundo hable del acontecimiento traumático participará en el trauma, curándolo o ulcerándolo. Absolutamente todo el mundo" (Cyrulnik, 2003, p. 73).

Las palabras y experiencias que utilizan las personas para relatar la vivencia del confinamiento a raíz de la pandemia pueden favorecer o limitar la resiliencia. "En [el] letargo psíquico persisten brasas de resiliencia sobre las que el medio puede soplar para reavivar la llama: comprender y soñar" (Cyrulnik, 2013, p. 167). Por ello, con el objetivo de favorecer la resiliencia a través del refuerzo de los vínculos sociales y el relato, nace la idea de este estudio vinculando estudiantes universitarios y utilizando métodos creativos útiles para superar los cambios vitales y aliviar la tensión (Irwin, 2006; Theron, 2012); aportando conciencia reflexiva (Archer, 2017) y salud comunitaria (Siles, 2019).

Por lo tanto, con el objetivo de compartir experiencias sobre la vivencia del confinamiento, se utilizó el espacio educativo y se eligió el intercambio de postales como instrumento para activar procesos de vinculación entre estudiantes. Se optó por este instrumento porque es un lenguaje que permite comprender y soñar en palabras e imágenes - dos partes claves del proceso de resiliencia- haciendo un ejercicio de introspección, de comprensión de una realidad compleja nunca vivida y una expresión de su mundo emocional hacia el otro -la otra persona receptora de su postal o de su respuesta-, y todo ello apoyado por la postal como expresión artística.

De este modo, el presente artículo nace con la intención de compartir una investigación cualitativa basada en una experiencia de innovación docente en el contexto universitario durante el período de confinamiento debido a la crisis sanitaria global provocada por el COVID-19. La investigación buscaba identificar factores de resiliencia y de no resiliencia a través del intercambio de postales digitales entre estudiantes de dos universidades diferentes que no se conocían entre ellos. Se invitó a los participantes a enfocar la temática de las postales en cómo estaban viviendo y transitando sus relaciones afectivas durante la pandemia.

\section{Metodología}

El estudio, de tipo cualitativo, analizó el contenido narrativo y visual de las postales, con el objetivo de indagar cómo el intercambio de postales puede facilitar la creación de un vínculo y la promoción de factores de resiliencia entre los estudiantes de España e Italia.

El contenido narrativo se trabajó a partir del modelo inductivo (Hernández et al., 2014). Utilizando el software Atlast.it se realizó una fase descriptiva de codificación abierta de los significados de los datos (Saldaña, 2016). Para luego dar paso a la fase interpretativa en la que se relacionan las tablas de co-ocurrencia y redes siguiendo la metodología de la teoría fundamentada (Miles et al., 2014), en este caso sobre el tema de la resiliencia y los vínculos.

En cuanto a las imágenes, se trabajaron desde dos perspectivas: los estudios de la cultura visual (Mirzoeff, 2003; Mitchell, 1995) entendidas como "constructoras de significados, como formas que nutren la subjetividad e 
identidad de las personas" (p. 238) y con una función social; y la investigación basada en las artes (Irwin, 2013; Springgay et al., 2005), donde se nos invita a pensar qué hacen las imágenes, poniendo el foco en el espacio relacional entre la creadora de la imagen y la investigadora, analizando qué sucede en esos espacios 'entre', en lugar de analizar las imágenes en sí mismas. Para ello, en un primer momento las imágenes de las postales fueron ordenadas por categorías comunes para, posteriormente, hacer un análisis interpretativo bajo los mismos criterios de factores de resiliencia y vínculo asociados.

El proceso de carteo involucró a los estudiantes del Máster de Relaciones de ayuda en contextos en vías de desarrollo y cooperación nacional e internacional de la Università Cattolica Sacro Cuore di Milano (UCSC) y los estudiantes del grado de Educación social de la Universitat de Barcelona (UB) que intercambiaron postales de manera virtual, bajo la coordinación de las profesoras que también participaron del intercambio. Previamente, los estudiantes de ambas partes fueron informados sobre los objetivos de la actividad y aceptaron participar en ella de forma voluntaria y confidencial.

El instrumento de la postal fue presentado a través del siguiente enunciado: creación de una postal que representara de forma reflexiva y visual las relaciones sociales del momento tan particular de confinamiento que estábamos viviendo. El envío tuvo lugar durante el mes de abril. El primero fue individual, y se enviaron a la vez 17 postales desde Milán hacia Barcelona y 26 desde Barcelona a Milán. El segundo envío, a modo de respuesta, fue grupal, específicamente, en grupos de 2 a 3 estudiantes. Milán envió 25 postales de respuesta a Barcelona y Barcelona 17 a Milán. El hecho de que el número de estudiantes no coincidiera, conllevó que algunas estudiantes de la UCSC respondieron a dos postales provenientes de Barcelona y que algunos grupos de 2 a 3 estudiantes de Barcelona se tuvieron que coordinar para responder conjuntamente a una sola estudiante de Milán.

\section{Resultados}

Los resultados descriptivos fueron trabajados a partir de una codificación abierta que generó 19 códigos:

1. Actitud prosocial: predisposición para establecer comunicación con el otro.

2. Actividades: descripción de actividades realizadas durante el confinamiento.

3. Autoaceptación y autoconocimiento: reflexión personal de la persona tal cual es.

4. Cambio como oportunidad: visión del COVID-19 como un cambio que traerá cosas positivas.

5. Contención emocional: intento por contener las emociones de la otra persona.

6. Empatía: ponerse en el lugar del otro.

7. Esperanza: actitud esperanzadora post-COVID-19.

8. Falta contacto: necesidad de contacto (físico y relacional).

9. Familia: revaloración de la familia.

10. Fortalecimiento relaciones: toma de consciencia sobre los vínculos más importantes.

11. Impacto emotivo: descripción del impacto emotivo que tiene la pandemia en la persona.

12. Incertidumbre: desconfianza y temor hacia un futuro incierto.

13. Introspección: reevaluación de todos los aspectos más personales.

14. Nuevas prioridades: restablecimiento de nuevas prioridades.

15. Proyección futuro: descripción de planes o ideas para el futuro.

16. Relaciones agresivas: observación de actitudes agresivas de la sociedad hacia el resto.

17. Resistencia: tendencia a volver atrás al día antes que comenzara la pandemia.

18. Solidaridad: conductas solidarias de la persona o comunidad.

19. Vivir el presente: disfrutar el momento. 
Los códigos más frecuentes (Grounded) fueron: Actitud prosocial ( $\mathrm{Gr} 47$ ), Fortalecimiento de las relaciones (Gr 28), Empatía (Gr 24) y Cambio como oportunidad (Gr 24).

El código Actitud prosocial (Gr 47) fue más frecuente al momento de responder las postales, evidenciando la intención de establecer contacto con el otro, como se refleja en los encabezados y finales de las postales. Esta categoría se complementa a su vez con la categoría de la Empatía (Gr 24) con frases como: "es un placer recibir tu mensaje y compartir este momento"; "gracias por compartir lo que estás viviendo con nosotras"; "estoy encantada de compartir este momento contigo".

El segundo código con mayor frecuencia, Fortalecimiento de las relaciones (Gr 28), agrupó reflexiones entorno a que a pesar de la distancia física impuesta por el confinamiento, las relaciones fueron reevaluadas por la persona y se reforzaron aquellas consideradas más importantes como la familia o amigos, con frases como: "Las relaciones interpersonales también han cambiado, se han fortalecido de forma más intensa"; "ahora entendemos la importancia de las relaciones"; "hablo más con gente que hacía tiempo que no lo hacía (familiares y amigos que viven lejos)".

En tercer lugar destaca Cambio como oportunidad, relacionado con el Fortalecimiento de las relaciones, lo cual refleja un importante factor de resiliencia al ver la adversidad como una oportunidad de cambio positivo en sus vidas y en la humanidad, por ejemplo: "Es una oportunidad para aumentar nuestra capacidad de adaptación y superación"; "Creo que dentro de lo negativo y de la gravedad de la situación también podemos adquirir aprendizajes positivos"; "De los diamantes no nace nada, del estiércol nace la flor".

Siguiendo con la fase interpretativa, se realizó una tabla de co-ocurrencia. Las tablas de co-ocurrencias muestran la relación y el nivel de significación entre los códigos, valor del c-coeficiente va de 0 a 1.

\section{Tabla 1}

Tabla cruzada de co-ocurrencias de los códigos más relevantes

\begin{tabular}{lll}
\hline Código & Gr & Código \\
\hline Actitud prosocial & 0,20 & Empatía \\
Cambio como oportunidad & 0,10 & Proyección futuro \\
Empatía & 0,19 & Contención emocional \\
Fortalecimiento relaciones & 0,11 & Familia \\
Fortalecimiento relaciones & 0,12 & Nuevas prioridades \\
Impacto emotivo & 0,26 & Incertidumbre \\
\hline
\end{tabular}

Los resultados muestran una predisposición para entrar en relación con el otro que se complementa con la empatía: "Querido amigo estamos todos en la misma situación"; "Nos reencontramos en lo que has escrito y es precioso"; "Leyendo tus palabras logramos percibir el dolor". Así como una reflexión sobre las relaciones que lleva a un cambio de prioridades y la familia adquiere un nuevo valor: "Entendemos perfectamente lo que dices, es momento de estar con la familia".

El análisis de una tabla cruzada entre el primer y el segundo envío de postales muestra cómo los códigos del ámbito social, emociones y empatía aumentan con el segundo envío, mientras que el fortalecimiento de las relaciones queda como una reflexión del primer envío, para describir el contexto o representar los aprendizajes que deja el confinamiento. 
Tabla 2

Comparación $1^{r}$ y $2^{\circ}$ envío

\begin{tabular}{lll}
\hline & $\mathbf{1}^{\text {r }}$ envío & $\mathbf{2}^{\circ}$ envío \\
\hline Actitud prosocial & $23,40 \%$ & $76,60 \%$ \\
Cambio como oportunidad & $50,00 \%$ & $50,00 \%$ \\
Contención emocional & $5,26 \%$ & $94,74 \%$ \\
Empatía & $8,33 \%$ & $91,67 \%$ \\
Fortalecimiento relaciones & $71,43 \%$ & $28,57 \%$ \\
\hline
\end{tabular}

La agrupación de códigos se realizó diferenciando entre códigos relacionados con aspectos negativos de la vivencia de la pandemia y confinamiento, y códigos que resaltan aspectos positivos. Ello permitió la creación de dos grupos:

- Factores de Resiliencia: actitud prosocial; actividades; autoaceptación y autoconocimiento; cambio como oportunidad; contención emocional; empatía; esperanza; familia; fortalecimiento de las relaciones; introspección; nuevas prioridades; proyección futuro; solidaridad; vivir el presente.

- Factores de no Resiliencia: falta de contacto; impacto emotivo; incertidumbre; relaciones agresivas; resistencia.

La resiliencia se genera producto de la interacción entre factores de resiliencia y de no resiliencia. Los primeros refuerzan o protegen los procesos de resiliencia en la persona y la comunidad; mientras que los factores de no resiliencia pueden dificultar u obstaculizar el desarrollo de procesos de resiliencia. El análisis a través de tablas cruzadas entre los factores de resiliencia y de no resiliencia muestran cómo los primeros aumentan en el segundo envío en comparación al primero. Más interesante aún es notar que los factores de no resiliencia disminuyen considerablemente del primer al segundo envío.

Tabla 3

Comparación Factores de Resiliencia y No Resiliencia

\begin{tabular}{lcc}
\hline & $\mathbf{1}^{\text {r }}$ envío & $\mathbf{2}^{\circ}$ envío \\
\hline Factores de No resiliencia & $84,61 \%$ & $15,39 \%$ \\
Factores de resiliencia & $46,35 \%$ & $53,65 \%$ \\
\hline
\end{tabular}

El último tipo de resultados es generado a través de una red semántica que refleja la interacción entre los conceptos a partir de la relación factores de resiliencia y de no resiliencia. La red fue creada en base a las correlaciones entre los conceptos. De esta se extrae que muchos de los factores de no resiliencia como la incertidumbre, el impacto emotivo o la falta de contacto generan espacios y oportunidades para la aparición y refuerzo de factores de resiliencia. 


\section{Figura 1}

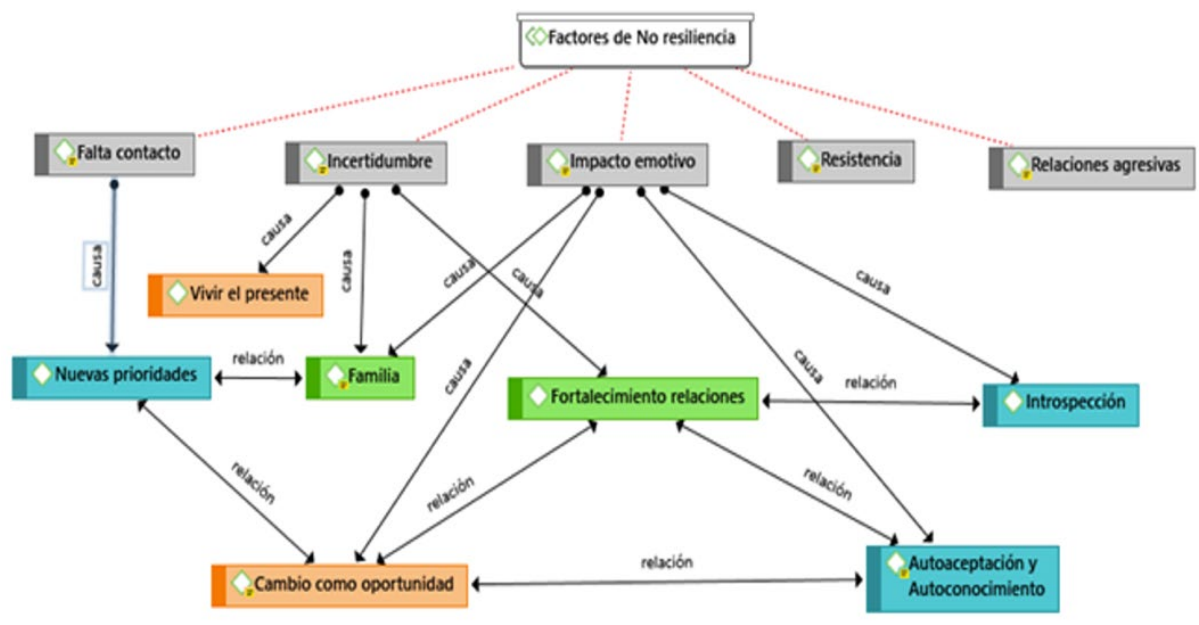

Los factores de no resiliencia tienden a ser menos en el segundo envío dando paso a los factores de resiliencia, tal como se refleja en la red (Figura 1). Igualmente, los factores de resiliencia pueden ser puestos en práctica gracias a los factores de no resiliencia, confirmando la interacción entre estos factores que genera resiliencia. En este contexto, el intercambio de postales genera mayor interacción y refuerza los vínculos promoviendo resiliencia.

Para el contenido iconográfico de las postales se han creado cuatro tablas para compilar las imágenes de cada envío de postal. Las tablas contienen tres columnas: una en la que se indica el elemento de análisis, una segunda con la cantidad de postales que cumplen con el criterio indicado y una tercera columna para observaciones.

Para el análisis de la ordenación de las imágenes se proponen cuatro bloques:

1. Qué imagen aparece en el lugar donde normalmente iría el sello. Nos sorprendió que aquellas postales que seguían la estructura tradicional de postal, al ser digital y que no se iba a enviar por correo postal, las estudiantes utilizaron de otro modo el espacio donde supuestamente iría el sello. En este caso, detectamos dos tendencias: o bien la estudiante utilizaba ese espacio para poner una fotografía suya a modo de presentación; o bien aprovechaban para compartir una imagen evocativa (ver algunos casos en la Figura 2).

2. Otro criterio de ordenación fue el tipo de composición. Por un lado, se ordenaron según si aparecía la cenefa típica de postal o no. Ahí nos sorprendió ver que algunas estudiantes tomaron plantillas similares a la postal en papel con la cenefa bicolor (ver Figura 3) mientras que otras estudiantes adoptaron formatos más libres. $\mathrm{Y}$, por otro lado, se dividieron las postales por si contenían una sola imagen - fotografía o ilustración extraída de alguna fuente existente-, varias imágenes, un dibujo realizado por la estudiante u otro tipo de composición.

3. Un último criterio de ordenación se basó en los motivos que aparecían en las imágenes. En este caso, se propusieron: frases evocadoras, pantallas, ventanas, personas, animales, naturaleza y ciudad.

Además, en las postales de 'respuesta' añadimos un factor que nos pareció interesante analizar, esto es, si había o no correspondencia visual con la imagen o las imágenes de la postal recibida. 


\section{Figura 2}

Cuatro ejemplos de imágenes evocadoras en el lugar donde iría el sello en correo postal
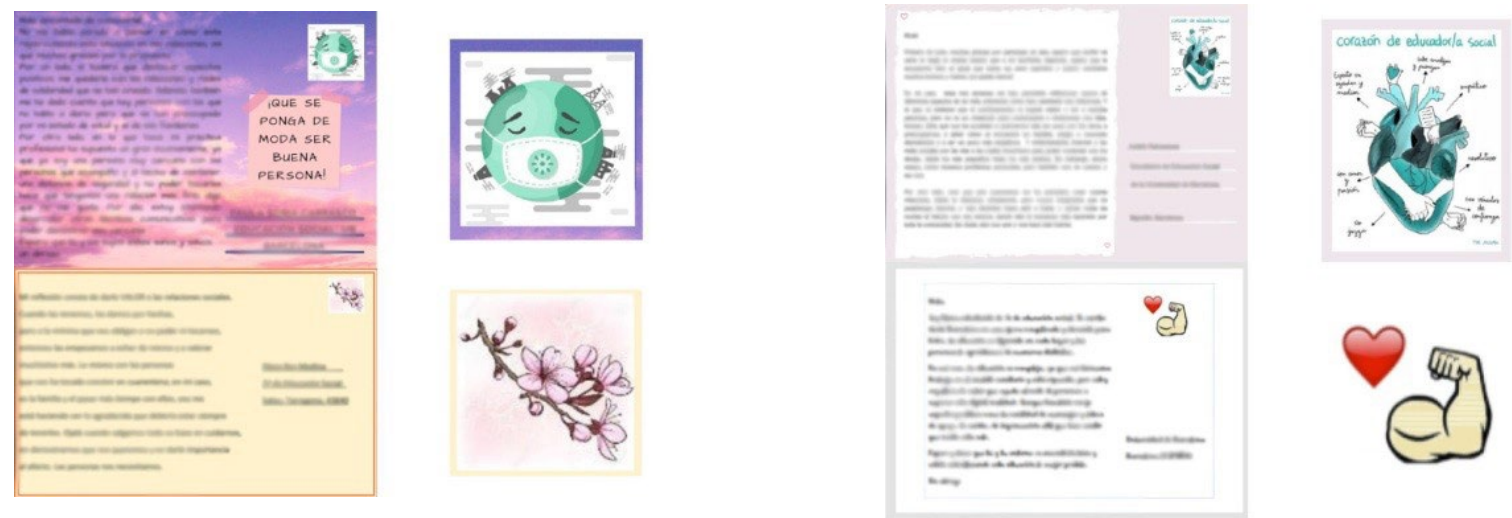

NOTA: a la derecha de cada postal se muestra una ampliación de la imagen evocadora en el lugar del sello.

\section{Figura 3}

Dos ejemplos en que las estudiantes utilizaron la cenefa típica de postal para su versión digital
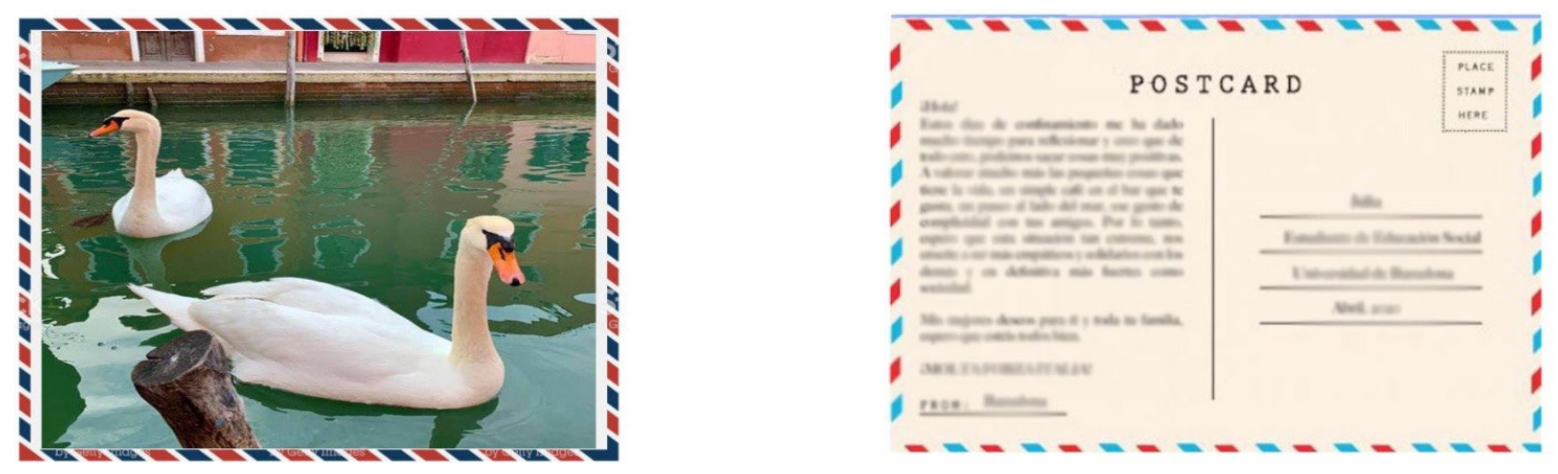

A continuación, la Tabla 4 recoge las imágenes de las postales realizadas por las estudiantes de la UCSC para ser enviadas a las estudiantes de la UB; la Tabla 5 compila el primer envío de las estudiantes de la UB hacia las estudiantes de la UCSC; la Tabla 6 muestra el vaciado de las postales que las estudiantes de la UCSC responden a las estudiantes de la UB; y, finalmente, la Tabla 7 recoge las respuestas de las estudiantes de la UB en relación con las de la UCSC. 
Tabla 4

$1^{r}$ envío desde Milán

\begin{tabular}{llll}
\hline & Elemento & Cantidad & Observaciones \\
\hline Lugar del sello & Retrato del emisor & 4 & \\
& Imagen evocadora & 4 & Imagen del pequeño príncipe, una bahía, un sol sonriente, una \\
& & & vista de ciudad tomada desde una ventana. \\
\hline \multirow{2}{*}{ Composición } & Cenefa típica de postal & 5 & \\
& Una sola imagen & 8 & \\
& Varias imágenes & 5 & \\
& Dibujo & 4 & \\
& Otros & - & \\
\hline \multirow{2}{*}{ Motivos } & Frases evocadoras & - & \\
& Pantallas & 2 & Imágenes que evocan a conceptos como: \\
& Ventanas & 4 & familiaridad, complicidad, puentes, vínculos, aislamiento, ternura. \\
& Personas & 11 & \\
& Animales & 1 & \\
& Naturaleza & 1 & \\
& Corazón & - & \\
& Abrazos & 2 &
\end{tabular}

Tabla 5

1r envío desde Barcelona

\begin{tabular}{llcll}
\hline \multicolumn{2}{c}{ Elemento } & Cantidad & Observaciones \\
\hline Lugar del sello & $\begin{array}{l}\text { Retrato del emisor } \\
\text { Imagen evocadora }\end{array}$ & 2 & 12 & $\begin{array}{l}\text { Árbol, paisaje, corazón, nube, pluma y tintero, símbolo de } \\
\text { mensajería, pregunta, sello de Italia, imagen de covid, flores, } \\
\end{array}$ \\
& & & emoji del brazo de ánimos. \\
\hline Composición & Cenefa típica de postal & 1 & \\
& Una sola imagen & 10 & \\
& Varias imágenes & 5 & Una con la técnica del collage \\
& Dibujo & 9 & Una con la técnica del collage \\
& Otros & 2 & Pintura, cianotipia \\
\hline Motivos & Frases evocadoras & - & \\
& Pantallas & 2 & \\
& Ventanas & 4 & \\
& Personas & 11 & \\
& Animales & 1 & \\
& Naturaleza & 1 & La mayoría de los vegetales que aparecen son flores \\
& Corazón & - & \\
& Abrazos & - & \\
Ciudad & 2 & Todas son imágenes de Barcelona con la Sagrada Familia \\
\hline
\end{tabular}


Tabla 6

$2^{\circ}$ envío desde Milán

\begin{tabular}{llcl}
\hline \multicolumn{2}{c}{ Elemento } & Cantidad & Observaciones \\
\hline Lugar del sello & Retrato del emisor & - & \\
& Imagen evocadora & 7 & Sol, flores, muñeca, mariposa, corazón, paisaje de lago. \\
\hline Composición & Cenefa típica de postal & 3 & \\
& Una sola imagen & 13 & \\
& Varias imágenes & 7 & \\
& Dibujo & 2 & \\
& Otros & 1 & Vídeo \\
Motivos & Frases evocadoras & 3 & \\
& Pantallas & 2 & \\
& Ventanas & - & \\
& Personas & 9 & \\
& Animales & 1 & \\
& Naturaleza & 8 & \\
& Corazón & 1 & \\
& Abrazos & 2 & \\
Ciudad & 3 & \\
\hline Correspondencia visual & 7 & A veces hay correspondencia conceptual, otras \\
& & compositiva, y otras a nivel formal y de colores \\
\hline
\end{tabular}

Tabla 7

$2^{\circ}$ envío desde Barcelona

\begin{tabular}{llll}
\hline & \multicolumn{1}{c}{ Elemento } & Cantidad & Observaciones \\
\hline Lugar del sello & Retrato del emisor & - & \\
& Imagen evocadora & 5 & Girasol, Barcelona, Flores, niñas, puño colectivo. \\
\hline Composición & Cenefa típica de postal & - & \\
& Una sola imagen & 6 & \\
& Varias imágenes & 5 & Una con la técnica del collage \\
& Dibujo & 4 & Algunas juegan con la imagen-texto \\
& Otros & & Pintura \\
\hline Motivos & Frases evocadoras & 2 & \\
& Pantallas & 4 & \\
& Ventanas & - & \\
& Personas & 1 & \\
& Animales & 6 & \\
& Naturaleza & 1 & \\
& Corazón & 4 & \\
Abrazos & 1 & \\
Ciudad & - & \\
\hline Correspondencia visual & - & \\
\hline
\end{tabular}

De acuerdo con Fischman y Cruder (2003), las imágenes desvelan una determinada historia. En el caso de las postales, la composición de imágenes desvela las historias de confinamiento de cada estudiante, tanto al principio del confinamiento con la primera postal, como a mediados de él, en la postal de respuesta. 
Analizando unas y otras nos damos cuenta de qué modo se ponen en juego factores de resiliencia y de no resiliencia y cómo estos transitan en los diferentes envíos. A continuación, exponemos los casos más relevantes por cada bloque.

\subsection{Lugar del sello}

Es interesante descubrir que, así como en el primer envío de postales 6 estudiantes encontraron pertinente presentarse mediante una fotografía suya, en el segundo envío de postales ninguna lo encontró necesario. Por otro lado, se dio un intercambio en el incremento de imágenes evocadoras. Así como en el primer envío, 12 postales de la UB utilizaron este recurso, sólo 5 lo usaron en el segundo envío. En cuanto a las postales de la UCSC, en el primer envío sólo 4 postales utilizaron imágenes evocadoras, mientras que en el segundo envío fueron 7. En cuanto a los motivos representados en las imágenes son bastante similares en todos los envíos.

\subsection{Composición}

Entre el primer y el segundo envío, tanto en las postales italianas como en las españolas, el uso de la cenefa disminuyó - se podría pensar que las estudiantes se toman la propuesta del ejercicio de forma más libre.

\subsection{Motivos}

Mirando cómo circulan los abrazos y los corazones, vemos que, en el primer envío de postales de las estudiantes de la UB, 7 de ellas contienen corazones y 4 imágenes de abrazos, mientras que en las de las estudiantes de la UCSC no aparece ninguno de estos elementos. En cambio, en las postales de respuesta, en las provenientes de la UB ya sólo en 1 postal aparece un corazón mientras que, en el caso de las postales italianas, en 2 de ellas aparecen abrazos y en una de ellas 1 corazón.

Otro motivo interesante para analizar es el de las ventanas y pantallas (ver Figura 4). Así como en el primer envío entre la UB y la UCSC circulan un total de 7 postales donde aparecen pantallas y 4 con ventanas, en el segundo envío, el de las respuestas, aparecen un total de dos postales con pantallas y 1 con ventanas. Esto nos lleva a pensar que tal vez las estudiantes empezaban a vivir con más resiliencia el encierro.

\section{Figura 4}

Tres ejemplos en que las estudiantes introdujeron imágenes de pantallas y ventanas en sus postales
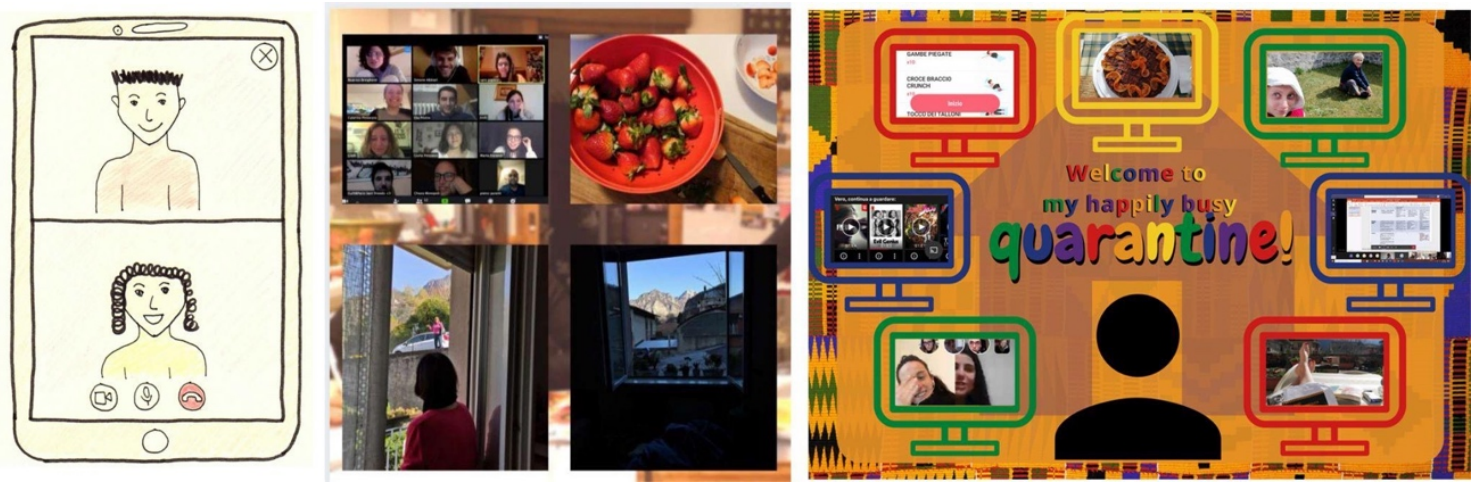


\subsection{Diálogo visual entre envío y respuesta}

Nos sorprendió ver que en las postales de respuesta de Italia había en 7 de ellas correspondencia visual con la que habían recibido, mientras que en las de España en ninguna de ellas se daba este diálogo. Vemos algunos ejemplos:

Hay correspondencias bastante literales, como por ejemplo el siguiente caso, en que responden a flores con flores (Figura 5).

\section{Figura 5}

Diálogo visual I
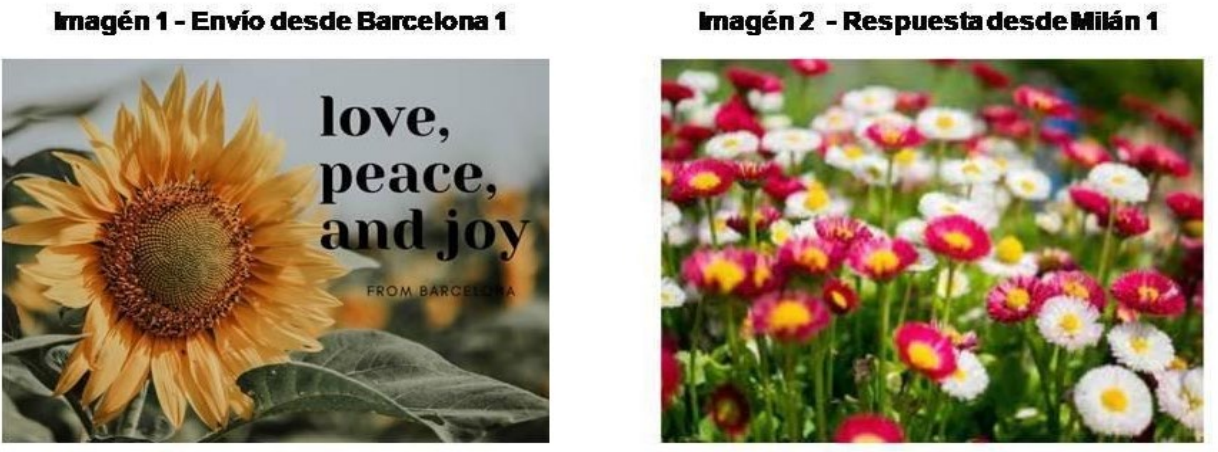

Otras son de tipo más compositivo. Por ejemplo, en las imágenes 3 y 4 (Figura 6) se corresponden compositivamente algunas zonas: el señor mayor de la imagen 3 con la barandilla y la escultura de la imagen 4; vegetación y arco iris de la parte superior izquierda de la imagen 3 con la forma arqueada de la vegetación de la parte izquierda de la imagen 4; la zona superior derecha ocupada por el perfil de mujer en la imagen 3 se corresponde con la mancha vegetal de la imagen 4; finalmente, la vegetación situada en la base de la imagen 3 se corresponde con el reflejo de vegetación de la imagen 4 . Otro ejemplo lo vemos en el caso de las imágenes 5 y 6 . En este caso se corresponde la mancha roja del corazón de la imagen 5 con la del coche de la imagen 6 (Figura 6); y el serpenteado de las velas de la imagen 5 con el serpenteado de la carretera de la imagen 6.

\section{Figura 6}

Diálogo visual II

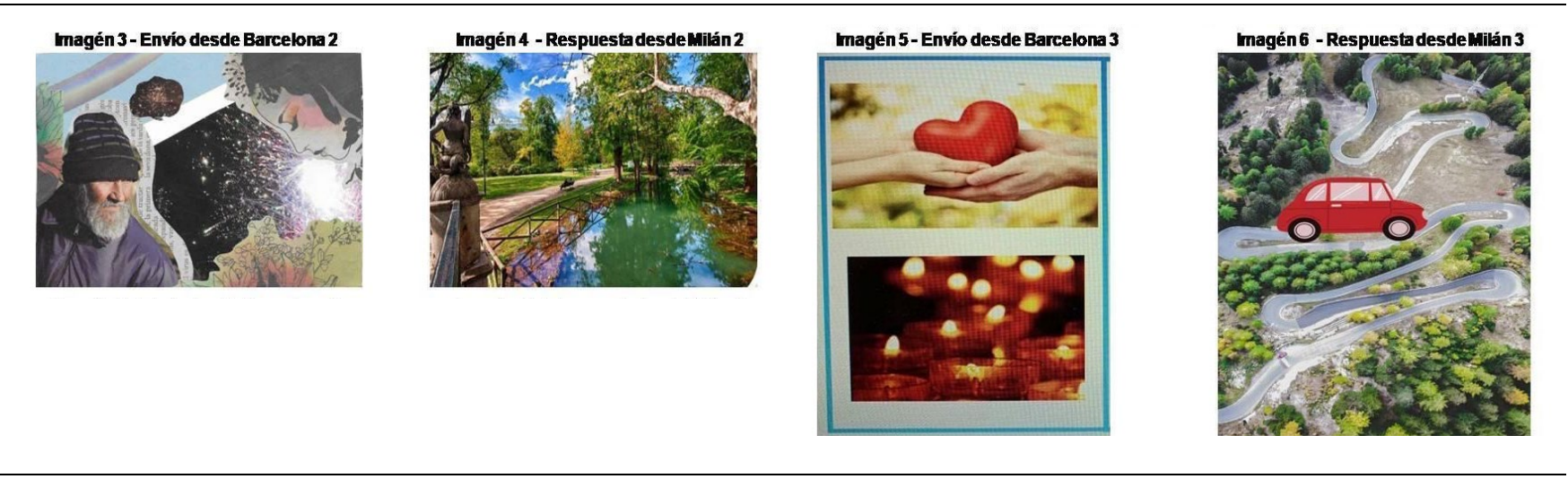


También encontramos correspondencias en el mensaje a transmitir. Por ejemplo, en el caso de las imágenes 7 y 8 (Figura 7) vemos una correspondencia en las ideas de unión, de manos y brazos alzados para conseguir un objetivo común que hace referencia a esa comunión para un mundo mejor.

Figura 7

Diálogo visual III

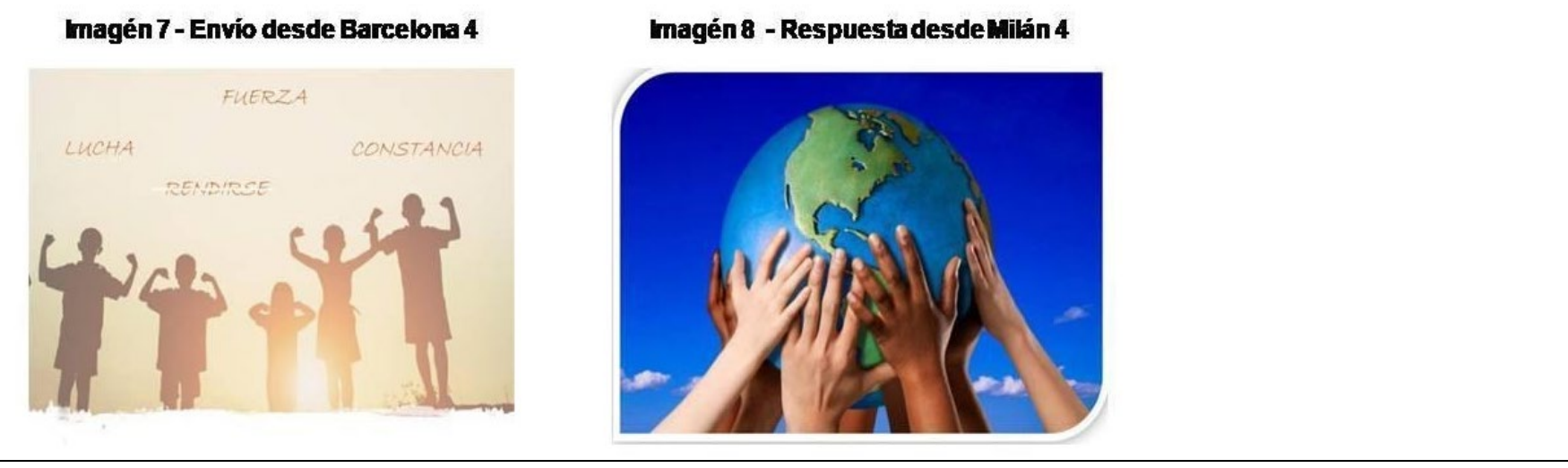

\section{Discusión}

Según MacDougall (2006, p. 2): "si vamos a obtener nuevos conocimientos a partir del uso de imágenes, estas vendrán en otras formas y por diferentes medios". Crear una postal para un estudiante desconocido era un reto. Se invitó a los alumnos a plasmar sus sentimientos y la forma en que estaban viviendo el encierro y materializarlo en un formato que combinara imagen y texto, es decir, en una postal digital. Eso les aportó un conocimiento sobre ellos mismos y sobre el entorno creativo. De acuerdo con Matthews (2019), el intercambio de postales funcionó "como un vehículo para visualizar la auto-transformación, y los cambios en sus circunstancias inmediatas" (p. 31). Además, las postales actuaron como una estrategia de narración que nos permitió, a profesores y alumnos, conectar "ámbitos cognitivos y afectivos entre sí, nuestra vida cotidiana y nuestros conocimientos y experiencias previas" (Sunday, 2018, p. 6). Ya que "La narración de historias es, en sí misma, parcialmente constitutiva de la elaboración de significados" (Sunday, 2018, p. 6). La creación de postales para una conversación entre estudiantes sobre sus vidas durante el confinamiento les permitió atender a sus "luchas tangibles" y ubicar sus experiencias "como una encarnación de la resiliencia creativa dentro de las sensibilidades" (Bowles, 2017, p. 108).

En una segunda fase, al tiempo que se recibía una postal y se respondía a ella, se realizaba un segundo ejercicio creativo en el que se invitaba a los participantes a reforzar la empatía hacia una carta de un desconocido. Al tener que interpretar la postal recibida para preparar una respuesta, sus emociones jugaron un papel importante (Hagtvedt et al., 2008). En ese nuevo reto se crearon nuevos conocimientos. Conectaron sus experiencias con quienes eran los estudiantes de otro país, qué les preocupaba, cómo se sentían encerrados en sus casas debido a una crisis sanitaria mundial. Y se les invitó a representar todo eso en una nueva postal.

La revisión y el análisis de las postales con fines de investigación ha proporcionado a las autoras de este estudio nuevos conocimientos sobre la resiliencia, los diálogos visuales y los mensajes cruzados que antes habían pasado desapercibidos. Exploramos las relaciones y conexiones entre las imágenes y el texto de las postales en cuanto a la forma en que ambos respondían de forma similar a los factores de resiliencia o de no resiliencia. Además, en 
el momento en que las imágenes y los textos generaron movimiento (Onsès, 2020), también se crearon nuevos conocimientos que no se tuvieron en cuenta al producir las postales.

Por otra parte, el envío de postales puso de manifiesto "la inestable relación entre ubicación e identidad" (Irwin et al., 2006, p. 79). Entre una postal y otra, los alumnos, sin moverse del mismo espacio (estaban confinados), se movían y reimaginaban su espacio y sus subjetividades. Analizar cómo había cambiado el tono, las imágenes y los mensajes, invitaba a pensar en los procesos y movimientos internos que los alumnos vivían durante los intercambios de postales. Esto muestra una tendencia a la resiliencia, la empatía y la rápida conexión entre desconocidos. Los alumnos hablaban de sí mismos a través de las creaciones visuales y textuales. Además, supuso que los estudiantes estaban abiertos "a un sentido de pertenencia que no estaba ligado a ningún lugar especial, sino a un 'sistema de movimiento'" (Kwon, 2000, p. 41).

Los resultados que surgieron de este proyecto confirman los elementos clave de los procesos de resiliencia que se refieren a las actitudes prosociales, lo que se ve claramente en el análisis tanto del texto como de las imágenes de las postales. Se trata de los acercamientos o ejercicios de autoaceptación y autoconocimiento, de introspección, que tuvieron lugar entre los envíos de las postales. La experiencia y su creación artística y textual vinculada a la vivencia del cambio como oportunidad. La proyección del futuro mientras se vive el presente. Y la importancia de los lazos y los vínculos. La experiencia surgida de la oportunidad de las circunstancias adversas subraya su impacto en la promoción de la resiliencia en los alumnos y profesores de ambos países. Además, subraya la necesidad de realizar actividades similares en la educación superior. Estar atentos a los estados vitales del alumnado y conectarlos con experiencias de enseñanza y aprendizaje es importante para establecer vínculos pedagógicos más eficaces y motivadores.

A su vez, el arte modifica esa expresión de la memoria herida, del presente cruel y del malestar por la falta de control. Cuando se crea una obra de arte (en este caso una postal), el autor crea una nueva interpretación de la realidad que le ayuda a curar las heridas o el dolor. Según Cyrulnik: "La curación, la comprensión y el conocimiento se convierten en sus armas de libertad" (Cyrulnik, 2015, p. 236). Los métodos visuales, en algunos casos, pueden crear un espacio para los participantes en el que "se sientan implicados en procesos emocionales y de apoyo" (Bowles, 2017, p. 116).

Por último, esta investigación confirma lo que Gugganig y Schor (2020) afirman sobre las tarjetas postales. Estas, como método de investigación, son "un medio abierto, semipúblico y polifacético que las hace propicias para el compromiso multimodal, las formas inventivas de análisis y los modos reflexivos de investigación crítica" (p. 23). Este tipo de propuesta abre nuevos enfoques para explorar las metodologías visuales en la investigación educativa, muy necesarias para ir más allá de los "límites de las palabras y las cosas" en la investigación (Metcalfe, 2016, p. 85).

En cuanto a los puntos fuertes y las limitaciones de la investigación, este trabajo presenta una investigación cualitativa que aporta nuevas ideas sobre las potencialidades de los métodos creativos -y especialmente de las postales- para trabajar la resiliencia con estudiantes universitarios. Además, aunque la resiliencia se ha estudiado en el ámbito educativo, los estudios recientes se centran en el periodo de escolarización (Lantieri, 2008; Mauer et al., 2016) o en la formación inicial del profesorado (Mansfield y Price, 2012), mientras que este trabajo se centra en estudiantes universitarios del ámbito de la educación social. En cuanto a posibles mejoras para el futuro, la investigación podría llevarse a cabo en más universidades y estudiantes para alcanzar una muestra más significativa, así como proponerse en un periodo más largo de la pandemia para un mejor proceso de seguimiento; o, esta misma investigación, ser analizada desde otros parámetros como pueden ser el temporal o 
el individual, siguiendo de forma más acurada cada envío y su correspondiente respuesta; o bien poniendo en contexto qué sucedía en la sociedad y la crisis sanitaria en cada momento del envío.

\section{Referencias}

Archer, C. (2017). Practice into Pedagogy into Practice: Collaborative Postcards from Hong Kong. The International Journal of Art \& Design Education, 36(1), 92-105. https://doi.org/10.1111/jade.12072

Bowles, L. R. (2017). Doing the Snap: Storytelling and Participatory Photography with Women Porters in Ghana. Visual Anthropology Review, 33(2), 107-118. https://doi.org/10.1111/var.12129

Brooks, S. K., Webster, R. K., Smith, L. E., Woodland L., Wessely S., Greenberg N., y Rubin, G. J. (2020). The psychological impact of quarantine and how to reduce it: Rapid review of the evidence. The Lancet, 395(10227), 912-920. https://doi.org/10.1016/S0140-6736(20)30460-8

Cyrulnik, B. (2002). Los patitos feos. La resiliencia: una infancia infeliz no determina la vida. Gedisa.

Cyrulnik, B. (2003). El murmullo de los fantasmas. Volver a la vida después de un trauma. Gedisa.

Cyrulnik, B. (2009). Autobiografía de un espantapájaros. Testimonios de resiliencia: el retorno a la vida. Gedisa.

Cyrulnik, B. (2010). Me acuerdo: el exilio de la infancia. Gedisa.

Cyrulnik, B. (2011). Morirse de Vergüenza. El miedo a la mirada del otro. Debate.

Cyrulnik, B. (2013). Sálvate. La vida te espera. Gedisa.

Cyrulnik, B. (2015). Las almas heridas. Las huellas de la infancia, la necesidad del relato y los mecanismos de la memoria. Gedisa.

European Centre for Disease Prevention and Control. (2020). Covid-19. https://qap.ecdc.europa.eu/public/extensions/COVID-19/COVID-19.html\#global-overview-tab

Fischman, G. E., y Cruder, G. (2003). Fotografías escolares como evento na pesquisa em educação. Educação $e$ Realidade, 28(2), 39-53.

Goldschmidt, K. (2020). The COVID-19 pandemic: Technology use to support the wellbeing of children. Journal of Pediatric Nursing, 53, 88-90. https://doi.org/10.1016/j.pedn.2020.04.013

Gugganig, M., y Schor, S. (2020). Multimodal Ethnography in/of/as Postcards. American Anthropologist, 122(3), 691-697. https://doi.org/10.1111/aman.13435

Hagtvedt, H., Hagtvedt, R., y Patrick, V. (2008). The Perception and Evaluation of Visual Art. Empirical Studies of the Arts, 26(2), 197-218. https://doi.org/10.2190/EM.26.2.d

Hernández, R., Fernández, C., y Baptista, M. (2014). Metodología de la investigación. McGraw-Hill Interamericana.

Irwin, E. C. (2006). Peter: A study of cumulative trauma from "robot" to "regular guy". En L. Carey (ed.), Expressive and creative arts methods for trauma survivors (pp. 93-113). Jessica Kingsley Publishers. 
Irwin, R. (2013). Becoming A/r/tography. Studies in Art Education: A Journal of Issues and Research, 54(3), 198215. https://doi.org/10.1080/00393541.2013.11518894

Irwin, R., Beer, R., Springgay, S., Grauer, K., y Xiong, G. (2006). The Rizhomatic Relations of A/r/tography. Studies in Art Education, 48(1),70-88. https://doi.org/10.1080/00393541.2006.11650500

Kwon, M. (2000). The Wrong Place. Art Journal, 59(1), 33-43. https://doi.org/10.1080/00043249.2000.10791980

Lantieri, L. (2008). Building Inner Resilience. Reclaiming Children and Youth, 17(2), 43-46.

López-Fernandez-Cao, M. (2015). Para qué el arte. Reflexiones entorno al arte y su educación en tiempos de crisis. Editorial Fundamentos.

MacDougall, D. (2006). The Corporeal Image. Film, Ethnography, and the Senses. Princeton University Press. https://doi.org/10.1515/9781400831562

Mansfield, C., y Price, A. (coords.). (2012). Keeping Cool: Embedding Resilience in the Initial Teacher Education Curriculum. Final Report 2012.

https://researchrepository.murdoch.edu.au/id/eprint/10522/1/PP9_1370_Mansfield_Report_2012_\%2 81\%29.pdf

Matthews, M. (2019). Agency and Social Construction: Practice of the Self in Art and Design. The International Journal of Art and Design Education, 38(1), 18-33. https://doi.org/10.1111/jade.12186

Maurer, M., Warren, K. E., y Pohl, C. (2016). The Postcard Initiative: Personal Communication from Students Can Increase Timely Compliance with Health Requirements. NASN School Nurse, 31(3), 147-49. https://doi.org/10.1177/1942602X15619757

Metcalfe, A. S. (2016). Educational research and the sight of inquiry: Visual methodologies before visual methods. Research in Education, 96(1), 78-86. https://doi.org.10.1177/0034523716664577

Miles, M., Huberman, A., y Saldaña, J. (2014). Qualitative data analysis: A methods sourcebook. Sage.

Mirzoeff, N. (2003). Una introducción a la cultura visual. Paidós.

Mitchell, W. J. T. (1995). Interdisciplinary and Visual Culture. The Art Bulletin, 77(4), 540-544.

Naciones Unidas. (2020, agosto). Informe de políticas: La educación durante la COVID-19 y después de ella. https://www.un.org/sites/un2.un.org/files/policy_brief_-_education_during_covid19_and_beyond_spanish.pdf

Onsès, J. (2020). Understanding how a learning phenomenon in which children were visually documenting their learning processes matters and intra-acts with the spaces of the school. Visual Studies. https://doi.org/10.1080/1472586X.2020.1799719

Organización para la Cooperación y el Desarrollo Económicos [OCDE]. (2020). Lessons for Education from COVID19: A Policy Maker's Handbook for More Resilient Systems. OECD Publishing. https://doi.org/10.1787/0a530888-en 
Orgilés M., Morales A., Delvecchio E., Francisco R., Pedro M., y Espada J. P. (2021). Coping behaviors and psychological disturbances in youth affected by the COVID-19 health crisis. Frontiers in Psychology, 12, Artículo 565657. https://doi.org/10.3389/fpsyg.2021.565657

Saldaña, J. (2016). The coding manual for qualitative researchers. Sage.

Save the Children (2020, mayo 8). Save the children advierte de que las medidas de ais/amiento social por la covid19 pueden provocar en los niños y niñas trastornos psicológicos permanentes como la depresión. https://www.savethechildren.es/notasprensa/save-children-advierte-de-que-las-medidas-deaislamiento-social-por-la-covid-19-pueden

Siles, S. (2019). El arte y la creatividad como nuevas formas de bienestar. Primera fase de ARTYS La Experimental, proyecto de Arte y Salud Comunitaria en la Colonia Experimental de Villaverde Alto (Madrid). EARI Educación Artística Revista de Investigación, 10, 150-167. https://doi.org/10.7203/eari.10.12608

Springgay, S., Irwin, R. L., y Wilson Kind, S. (2005). A/r/tography as Living Inquiry Through Art and Text. Qualitative Inquiry, 11(6), 897-912. https://doi.org/10.1177/1077800405280696

Sunday, K. E. (2018). Drawing and Storytelling as Political Action: Difference, Plurality and Coming into Presence in the Early Childhood Classroom. The International Journal of Art and Design Education, 37(1), 6-17. https://doi.org/10.1111/jade.12097

Theron, L. C. (2012). Does visual participatory research have resilience-promoting value? Teacher experiences of generating and interpreting drawings. South African Journal of Education, 32(4), 381-392. https://doi.org/10.15700/saje.v32n4a656

World Health Organization [WHO]. (2020). WHO director general's opening remarks at the media briefing on COVID-19 - 11 March 2020. https://www.who.int/director-general/speeches/detail/who-directorgeneral-s-opening-remarks-at-the-media-briefing-on-covid-19---11-march-2020 